\title{
Does the minimal occlusive volume technique provide adequate endotracheal tube cuff pressure to prevent air leakage?: a prospective, randomized, crossover clinical study
}

\author{
Ha Yeon Park, Mina Kim, and Junyong In
}

Received March 16, 2020

Revised April 5, 2020

Accepted April 11, 2020

Department of Anesthesiology and Pain Medicine, Dongguk University Ilsan Hospital, Goyang, Korea

\begin{abstract}
Background: Methods of determining proper endotracheal tube (ETT) cuff pressure to prevent air leakage include the minimal occlusive volume (MOV) technique, which uses auscultation, and the spirometer technique, which directly measures inspiratory and expiratory breathing volumes. Spirometers may measure even small air leakage, therefore, the spirometer technique requires a higher cuff pressure than the MOV technique to completely seal the airway. This study aimed to evaluate the difference in cuff pressure between the two techniques used to seal the airway.
\end{abstract}

Methods: Thirty-five female patients were intubated using an ETT with a cuff, and cuff inflation was performed with both techniques at a 10-min interval in random order-the MOV technique and then the spirometer technique or vice versa. The cuff pressure was measured at each period.

Results: The cuff pressures were $16.7 \pm 4.4 \mathrm{cmH}_{2} \mathrm{O}$ and $18.7 \pm 5.2 \mathrm{cmH}_{2} \mathrm{O}$ for the MOV and spirometer techniques, respectively. The cuff pressure for the spirometer technique was $2.0 \mathrm{cmH}_{2} \mathrm{O}$ higher than that for the MOV technique and this difference was statistically significant (95\% confidence interval, $0.7-3.3 ; \mathrm{P}=0.003)$. Considering the upper end $(3.3 \mathrm{~cm}$ $\left.\mathrm{H}_{2} \mathrm{O}\right)$ of the $95 \%$ confidence interval and the size of one scale unit $\left(2.0 \mathrm{cmH}_{2} \mathrm{O}\right)$ of a manometer, the difference in cuff pressure was up to $4 \mathrm{cmH}_{2} \mathrm{O}$ in practice.

\section{Corresponding author} Junyong In, M.D., Ph.D. Department of Anesthesiology and Pain Medicine, Dongguk University Ilsan Hospital, 27 Dongguk-ro, Ilsandong-gu, Goyang 10326, Korea Tel: 82-31-961-7875

Fax: 82-31-961-7864

E-mail: dragona1@dumc.or.kr
Conclusions: Even though the air leakage sound disappears on auscultation, unlike the previous recommendation, the airway sealing would be completed only by increasing the cuff pressure by approximately $4 \mathrm{cmH}_{2} \mathrm{O}$.

Keywords: Airway management; Anesthesia; Endotracheal; Manometry; Minimal occlusive volume; Spirometer.

\section{INTRODUCTION}

The endotracheal tube (ETT) with a cuff is generally used in mechanically ventilated patients. ETT cuff sealing is necessary to ensure mechanical ventilation with adequate tidal volume and to prevent aspiration [1,2]. A higher cuff pressure can result in complete airway sealing without air leakage, however, increased cuff pressure can contribute to tracheal injuries [3-7]. Therefore, it is important to maintain proper cuff pressure that guarantees airway sealing without overinflating the ETT cuff.

Among various cuff inflation methods to seal the airway,

This is an Open Access article distributed under the terms of the Creative Commons Attribution Non-Commercial License (http://creativecommons.org/licenses/by-nc/4.0) which permits unrestricted non-commercial use, distribution, and reproduction in any medium, provided the original work is properly cited.

Copyright (C) the Korean Society of Anesthesiologists, 2020 
are the minimal occlusive volume (MOV) technique using auscultation and the spirometer technique that directly measures inspiratory and expiratory breathing volumes. The MOV technique has the advantage that it can be easily applied with a stethoscope after tracheal intubation [8-10], while the spirometer, which is embedded in an anesthesia station, has the advantage of being able to monitor the air leakage in real time, and to be a more accurate method to confirm the existence and the degree of the air leakage [10].

Previous studies have reported higher cuff pressures for the MOV technique [10-12] than for the spirometer technique. However, we expected that the cuff pressure determined by the spirometer technique would be higher than that determined by the MOV technique because a spirometer is able to detect even small air leakage. A difference in cuff pressure beyond the minimum measurement unit (2 $\mathrm{cmH}_{2} \mathrm{O}$ ) of the manometer between the two techniques cannot be neglected; therefore, the cuff pressure should be adjusted for the complete sealing of the airway. Hence, this study aimed to compare the cuff pressure using the two techniques with a mean difference of $2 \mathrm{cmH}_{2} \mathrm{O}$.

\section{MATERIALS AND METHODS}

This prospective randomized crossover clinical study was approved by the Institutional Review Board of the Dongguk University Ilsan Hospital (no. DUIH IRB 2017-10-004) and was registered on www.clinicaltrials.gov (no. NCT03385044). Written informed consent was obtained from the patients who met the eligibility criteria. Thirty-five patients aged between 20 to 60 years who were scheduled for elective laparoscopic gynecologic surgical procedure from March to October 2018 were included. Each patient was intubated and cuff inflation was performed with both techniques at a 10-min interval in random order-the MOV technique first and then spirometer technique (a spirometer built in an anesthesia machine [Carestation $650^{\mathrm{TM}}$, Datex-Ohmeda Inc., USA], Sequence MS) or vice versa (Sequence SM). The cuff inflation and pressure were measured only once in each technique. Patients with an anticipated difficult intubation, having a history of difficult intubation, body mass index $>30 \mathrm{~kg} / \mathrm{m}^{2}$, and known anatomical laryngotracheal abnormalities were excluded.

General anesthesia was induced using an intravenous bolus of propofol $2 \mathrm{mg} / \mathrm{kg}$, remifentanil infusion of $2.0 \mathrm{ng} /$ $\mathrm{ml}$ using target-controlled infusion, and the neuromuscular blockade was achieved with rocuronium $0.6 \mathrm{mg} / \mathrm{kg}$. Af- ter confirming that the patients were been fully relaxed, they were intubated with a $7.0 \mathrm{~mm}$ internal diameter endotracheal tube (TaperGuard ${ }^{\mathrm{TM}}$ Oral/Nasal tracheal Tube, Covidien, Mexico). After the endotracheal intubation was performed, we inflated the cuff balloon with air, using a 10$\mathrm{ml}$ syringe until the cuff pressure reached $30 \mathrm{cmH}_{2} \mathrm{O}$. The cuff was progressively inflated by injecting air in $0.5 \mathrm{ml}$ increments until it reaches $30 \mathrm{cmH}_{2} \mathrm{O}$. The measurement was taken with a manometer (VBM Medizintechnik, Sulz am Neckar, Germany) connected to the cuff balloon with a three-way stopcock. The cuff pressure was measured at the end of expiration. Anesthesia was maintained with sevoflurane $1.5-2.0 \%$ in combination with air and oxygen at the fraction of inspired oxygen of 0.4. The patients were ventilated using a volume-controlled ventilation with $2.0 \mathrm{~L} / \mathrm{min}$ of fresh gas flow. After the patient was positioned and carbon dioxide insufflation for the laparoscopic surgery was performed, the tidal volume and the respiratory rate were set to reach a peak inspiratory pressure of $25 \mathrm{cmH}_{2} \mathrm{O}$, which was maintained till the end of the study. Subsequently, the initial ratio of expiration to inspiration volume $\left(\mathrm{V}_{\mathrm{E}} / \mathrm{V}_{\mathrm{I}}\right.$ ratio $)$ was measured. The manometer was connected to a $10-\mathrm{ml}$ syringe and the pilot balloon of the endotracheal tube via a three-way stopcock. After stabilization for $5 \mathrm{~min}$, the cuff was completely deflated. The cuff was considered empty when no more air could be removed on aspiration with the syringe.

The 35 patients were randomly allocated via opaque sealed envelopes to either Sequence MS or Sequence SM (Fig. 1) using internet-based random numbers (http:// www.randomizer.org). The random number generation and allocation process was managed by a researcher who did not perform the techniques and data collection. While the patients and data analyst were blinded to allocation, the researcher, who performed the two techniques during the study period could not be blinded to the allocation.

Patients in Sequence MS received the MOV technique during the first period and the spirometer technique during the second period. Patients in Sequence SM were treated in the reverse order. There was a 10 min interval with a cuff pressure of $30 \mathrm{cmH}_{2} \mathrm{O}$ between the two periods. The cuff pressure and the volume of air injected into the cuff were measured and recorded by an anesthetic nurse who did not participate in this study. The cuff pressure was measured at the end of expiration when the airway pressure is the lowest in a respiratory cycle. In the MOV technique, after checking that the cuff had been completely de- 


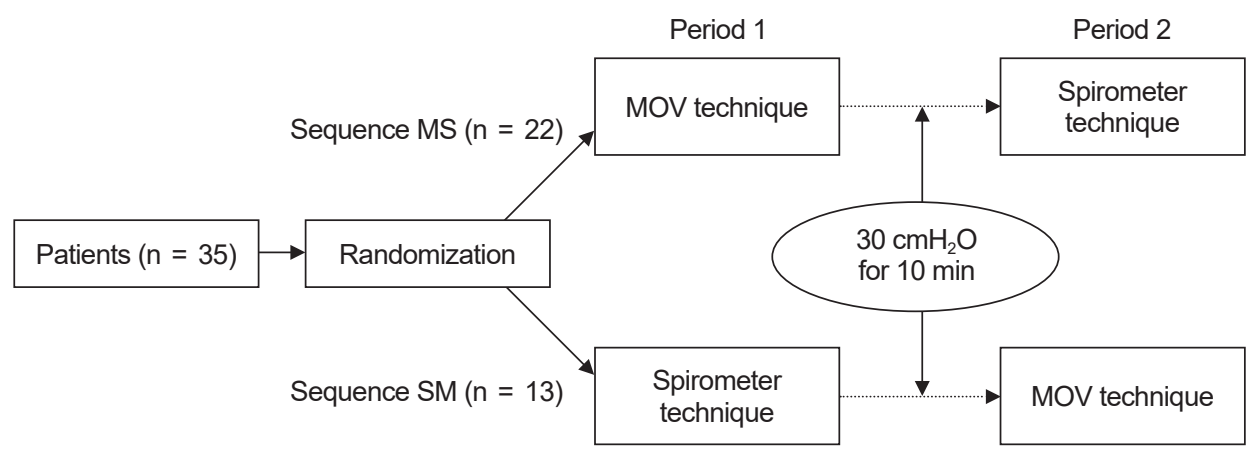

Fig. 1. Study protocol. Patients in Sequence MS received the minimal occlusive volume technique during the first period and the spirometer technique during the second period. Patients in Sequence SM were treated in the reverse order. MOV: minimal occlusive volume.

flated, the cuff was then slowly inflated with $0.2 \mathrm{ml}$ increments at every inspiratory moment until the air leakage sound disappeared. The air leakage sound was identified with a stethoscope at the mouth of the patient to ensure the absence of the air leakage. When the air leakage sound disappeared, the cuff pressure and the volume of air injected into the cuff were recorded. In the spirometer technique, after the cuff was completely deflated, the cuff was slowly inflated with $0.2 \mathrm{ml}$ increments using a syringe. The cuff was inflated in each patient during the inspiratory phase. When the final $V_{E} / V_{I}$ ratio of the spirometer reached the initial value, the cuff pressure and the volume of air injected into the cuff were recorded.

After all the measurements in each patient, the cuff pressure was maintained at a value for which no leakage existed throughout the rest of the surgery.

\section{Statistical analysis}

The primary outcome was the cuff pressure at the moment when the air leakage disappeared, which was confirmed by the two techniques. The secondary outcome was the volume of air in the cuff when the air leakage disappeared. Clinical studies that have studied clinical complications due to cuff pressure, generally set a difference above $5 \mathrm{cmH}_{2} \mathrm{O}$ as a significant difference [13]. However, since this study is looking at the difference in cuff pressure associated with air leakage prevention, we set $2 \mathrm{cmH}_{2} \mathrm{O}$ to be the minimum unit of measurement and measurement error, to determine a difference in the cuff pressure. In other words, if it is more than this difference, cuff inflation should be adjusted for adequate sealing.

According to the prior study [14], it is established that the standard deviation of pressure of the ETT cuff that was sealed using MOV technique is $3.8 \mathrm{cmH}_{2} \mathrm{O}$. Given the ex-
Table 1. Patient Characteristics

\begin{tabular}{lc}
\hline \multicolumn{1}{c}{ Variable } & Patients $(\mathrm{n}=35)$ \\
\hline Age $(\mathrm{yr})$ & $39 \pm 8$ \\
Height $(\mathrm{cm})$ & $160 \pm 5$ \\
Weight $(\mathrm{kg})$ & $61 \pm 6$ \\
Tilt angle of surgical table $\left({ }^{\circ}\right)$ & $13.0(11.0,15.5)$ \\
\hline
\end{tabular}

Values are presented as mean \pm SD or median $(1 \mathrm{Q}, 3 \mathrm{Q})$.

pected pressure difference of $2 \mathrm{cmH}_{2} \mathrm{O}, 31$ patients were required for a significance level of 0.05 and power of $80 \%$ applying a crossover design. Thirty-five patients were recruited considering the dropout rate of $10 \%$.

Data were check for normality with QQ plots. The cuff pressure and the air volume were analyzed using linear mixed models that included the two sealing techniques, sequence MS/SM, and periods, with a random effect for each patient [15]. The initial $V_{E} / V_{I}$ ratio and the final $V_{E} / V_{I}$ ratio were compared using paired $t$-tests.

R software version 3.5.2 (R Core Team, 2018; https:// www.r-project.org/) and additional nlme library (R package version 3.1-137, Pinheiro J, Bates D, DebRoy S, Sarkar D and R Core Team, 2018; http://CRAN.R-project.org/ package $=$ nlme) were used for data entry and analysis. Data were presented as mean \pm standard deviation or mean difference (95\% confidence interval [CI]). Statistical significance was defined as $\mathrm{P}<0.05$.

\section{RESULTS}

Table 1 shows the demographic characteristics of the patients enrolled in the study. There were no carryover and period effects on cuff pressure and cuff volume. The cuff pressure was $16.7 \pm 4.4 \mathrm{cmH}_{2} \mathrm{O}$ in the MOV technique, while a cuff pressure of $18.7 \pm 5.2 \mathrm{cmH}_{2} \mathrm{O}$ was measured in the spirometer technique. The cuff pressure difference be- 
Table 2. Endotracheal Tube Cuff Pressure and Cuff Volume

\begin{tabular}{lcccc}
\hline \multicolumn{1}{c}{ Variable } & MOV technique & Spirometer technique & Mean difference $(95 \%$ confidence interval) & P value \\
\hline Cuff pressure $\left(\mathrm{cmH}_{2} \mathrm{O}\right)$ & $16.7 \pm 4.4$ & $18.7 \pm 5.2$ & $2.0(0.7-3.3)$ & 0.003 \\
Cuff volume $(\mathrm{ml})$ & $3.9 \pm 1.2$ & $4.2 \pm 1.2$ & $0.3(0.1-0.5)$ & 0.013 \\
\hline
\end{tabular}

Values are presented as mean \pm SD. MOV: minimal occlusive volume.

tween the two sealing techniques was $2.0 \mathrm{cmH}_{2} \mathrm{O}(95 \% \mathrm{CI}$, 0.7-3.3; $\mathrm{P}=0.003$ ), which means that the cuff pressure by the spirometer technique was approximately $3.3 \mathrm{cmH}_{2} \mathrm{O}$ higher than those of the MOV technique (Table 2).

The difference between the volume of the air in the cuffs was $0.3 \mathrm{ml}$ (95\% CI, 0.1-0.5; $\mathrm{P}=0.013)$, which means that the volume of the air in the cuffs sealed by the spirometer technique was approximately $0.5 \mathrm{ml}$ larger than those sealed by the MOV technique (Table 2).

In the spirometer technique, the initial $\mathrm{V}_{\mathrm{E}} / \mathrm{V}_{\mathrm{I}}$ ratio measured at the beginning of the study were compared with the final $V_{\mathrm{E}} / \mathrm{V}_{\mathrm{I}}$ ratio at the time when there was no air leakage. No significant difference was observed between the initial $V_{\mathrm{E}} / \mathrm{V}_{\mathrm{I}}$ ratio and the final $\mathrm{V}_{\mathrm{E}} / \mathrm{V}_{\mathrm{I}}$ ratio $(0.976 \pm 0.021$, $0.975 \pm 0.020$, respectively, mean difference $=0.001,95 \%$ CI, $-0.002-0.004 ; \mathrm{P}=0.539$ ).

\section{DISCUSSION}

As expected, the cuff pressure in the spirometer technique was higher than the cuff pressure in the MOV technique, which was as high as $2.0 \mathrm{cmH}_{2} \mathrm{O}(95 \% \mathrm{CI}, 0.7-3.3)$. In other words, even though the sealing was determined by auscultation, a higher cuff pressure was required to seal the airway completely. Considering the $95 \% \mathrm{CI}$, the difference is up to $3.3 \mathrm{cmH}_{2} \mathrm{O}$, which also exceeds the manometer's margin of error. Therefore, after the air leakage sound disappears during the MOV technique, the cuff pressure should be increased by two scale units (approximately 4 $\mathrm{cmH}_{2} \mathrm{O}$ ) of a manometer to prevent air leakage. This cuff pressure difference is less than $5 \mathrm{cmH}_{2} \mathrm{O}$, which is meaningful in clinical studies of airway complications associated with high cuff pressure [13]. Furthermore, the increased cuff pressure would not reach the recommended cuff pressure of $30 \mathrm{cmH}_{2} \mathrm{O}$ from the guidelines [16,17]. Hence, increasing the cuff pressure about $4 \mathrm{cmH}_{2} \mathrm{O}$ would not add to the risk of clinical complications. If the cuff pressure cannot be measured, consider adding $0.5 \mathrm{ml}$ air which is the upper limit of the $95 \%$ CI.

Unlike previous studies [10-12], this study showed that the cuff pressure was low when measured by the MOV technique. We slowly inflated the cuff with air with $0.2 \mathrm{ml}$ increment at every inspiratory moment until the air leakage sound heard by the stethoscope disappeared. This precise and stepwise inflation of the cuff may have resulted in the lower cuff pressure without air leakage sounds from the MOV technique.

Many anesthesiologists check the appropriateness of the sealing by referring to the cuff pressure through manually palpating the ETT pilot balloon. They stop inflating the pilot balloon when they feel it is tight enough. However, digital balloon palpation corresponds poorly with the measured ETT cuff pressure [18-20]. Furthermore, when the anesthesiologists manually palpate the pilot balloon to measure the pressure, they usually underestimate them causing over-inflation of the cuffs $[8,9]$. Hence, it is important to seal the airway using proper methods for the patients' safety. Humans' sensitivity for hearing sound is different individually. In other words, one can hear a leakage sound to some extent, while the other one cannot hear the fine or detail sounds caused by the air leakage. The operating room noise will also interfere significantly. For these reasons, some researchers regard that the MOV technique could result in an inadequate airway sealing, with either very high or very low cuff pressures [21,22].

Using the spirometer technique which we have dealt with, physicians now can continuously monitor the air leakage. It can be achieved using a spirometer already built in the anesthesia machine by checking inspiratory and expiratory volumes just like the spirometer technique performed in this study. Sealing ETT cuff properly and monitoring the air leakage continuously would contribute to patients' safety.

Cuff pressure difference of $2.0 \mathrm{cmH}_{2} \mathrm{O}(95 \% \mathrm{CI}, 0.7-3.3)$ may look insignificant, and may be regarded as a measurement error or as the minimum measurement unit of the manometer that can be ignored. However, in this study, we found out the fact that a small amount of the air leakage still exists when the ETT cuff is sealed using the MOV technique. This indicates that when using the MOV technique, an additional pressure of approximately $4 \mathrm{cmH}_{2} \mathrm{O}$ is required to completely seal the airway without leaking air. 
This study has some limitations. This study included only female patients undergoing gynecological surgery. Therefore, the study results may not be applicable for males or other sizes of ETT, but we tried to reduce other variables by using the same ETT $(7.0 \mathrm{~mm})$ size in patients with similar characteristics. In addition, it would be helpful if there was $\mathrm{V}_{\mathrm{E}} / \mathrm{V}_{\mathrm{I}}$ ratio at the time the air leakage sound disappeared in the MOV technique. However, since many studies on air leakage used cuff pressure, this study also determined the presence of air leakage based on cuff pressure. Therefore, it was expected that even if the $V_{E} / V_{I}$ ratios were measured directly in the MOV technique, it would not be significantly different from the results of this study. Nevertheless, further research on direct measurement would be helpful.

In conclusion, even if the air leakage sound disappears on a stethoscope in the MOV technique, air leakage may still occur. Therefore, unlike the previous recommendation, the airway sealing would be completed only by increasing the cuff pressure by approximately $4 \mathrm{cmH}_{2} \mathrm{O}$. Further, if the cuff pressure cannot be measured, adding $0.5 \mathrm{ml}$ of air into the cuff would be helpful.

\section{CONFLICTS OF INTEREST}

No potential conflict of interest relevant to this article was reported.

\section{AUTHOR CONTRIBUTIONS}

Conceptualization: Junyong In, Ha Yeon Park. Data acquisition: Mina Kim. Formal analysis: Junyong In. Supervision: Junyong In. Writing_original draft: Ha Yeon Park, Mina Kim. Writing_review \& editing: Ha Yeon Park, Junyong In.

\section{ORCID}

Ha Yeon Park, https://orcid.org/0000-0002-8347-349X

Mina Kim, https://orcid.org/0000-0002-1532-1750

Junyong In, https://orcid.org/0000-0001-7403-4287

\section{REFERENCES}

1. Vyas D, Inweregbu K, Pittard A. Measurement of tracheal tube cuff pressure in critical care. Anaesthesia 2002; 57: 275-7.

2. Mahul P, Auboyer C, Jospe R, Ros A, Guerin C, el Khouri Z, et al. Prevention of nosocomial pneumonia in intubated patients: respective role of mechanical subglottic secretions drainage and stress ulcer prophylaxis. Intensive Care Med 1992; 18: 20 5 .

3. Mandøe H, Nikolajsen L, Lintrup U, Jepsen D, Mølgaard J. Sore throat after endotracheal intubation. Anesth Analg 1992; 74: 897-900

4. Curiel García JA, Guerrero-Romero F, Rodríguez-Morán M. [Cuff pressure in endotracheal intubation: should it be routinely measured?]. Gac Med Mex 2001 137: 179-82. Spanish.

5. Hähnel J, Treiber H, Konrad F, Eifert B, Hahn R, Maier B, et al. [A comparison of different endotracheal tubes. Tracheal cuff seal, peak centering and the incidence of postoperative sore throat]. Anaesthesist 1993 42: 232-7. German.

6. Liu J, Zhang X, Gong W, Li S, Wang F, Fu S, et al. Correlations between controlled endotracheal tube cuff pressure and postprocedural complications: a multicenter study. Anesth Analg 2010; 111: 1133-7.

7. Jensen PJ, Hommelgaard P, Søndergaard P, Eriksen S. Sore throat after operation: influence of tracheal intubation, intracuff pressure and type of cuff. Br J Anaesth 1982; 54: 453-7.

8. Fernandez R, Blanch L, Mancebo J, Bonsoms N, Artigas A. Endotracheal tube cuff pressure assessment: pitfalls of finger estimation and need for objective measurement. Crit Care Med 1990; 18: 1423-6.

9. Braz JR, Navarro LH, Takata IH, Nascimento Júnior P. Endotracheal tube cuff pressure: need for precise measurement. Sao Paulo Med J 1999; 117: 243-7.

10. Bolzan DW, Gomes WJ, Faresin SM, de Camargo Carvalho AC, De Paola AA, Guizilini S. Volume-time curve: an alternative for endotracheal tube cuff management. Respir Care 2012; 57: 2039-44.

11. Bolzan DW, Gomes WJ, Peixoto TC, Faresin SM, Carvalho AC, De Paola AA, et al. Clinical use of the volume-time curve for endotracheal tube cuff management. Respir Care 2014; 59: 1628-35.

12. Almarakbi WA, Kaki AM. Tracheal tube cuff inflation guided by pressure volume loop closure associated with lower postoperative cuff-related complications: prospective, randomized clinical trial. Saudi J Anaesth 2014; 8: 328-34.

13. Lizy C, Swinnen W, Labeau S, Poelaert J, Vogelaers D, Vandewoude K, et al. Cuff pressure of endotracheal tubes after changes in body position in critically ill patients treated with mechanical ventilation. Am J Crit Care 2014; 23: e1-8.

14. Al-Metwalli RR, Al-Ghamdi AA, Mowafi HA, Sadek S, Abdulshafi M, Mousa WF. Is sealing cuff pressure, easy, reliable and safe technique for endotracheal tube cuff inflation?: a compar- 
ative study. Saudi J Anaesth 2011; 5: 185-9.

15. Senn S. Cross-over trials in clinical research. 2nd ed. West Sussex, John Wiley \& Sons. 2002. p. 35-88.

16. American Thoracic Society, Infectious Diseases Society of America. Guidelines for the management of adults with hospital-acquired, ventilator-associated, and healthcare-associated pneumonia. Am J Respir Crit Care Med 2005; 171: 388-416.

17. Lorente L, Blot S, Rello J. Evidence on measures for the prevention of ventilator-associated pneumonia. Eur Respir J 2007; 30: 1193-207.

18. Hoffman RJ, Parwani V, Hahn IH. Experienced emergency medicine physicians cannot safely inflate or estimate endotracheal tube cuff pressure using standard techniques. Am J Emerg Med 2006; 24: 139-43.
19. Parwani V, Hoffman RJ, Russell A, Bharel C, Preblick C, Hahn IH. Practicing paramedics cannot generate or estimate safe endotracheal tube cuff pressure using standard techniques. Prehosp Emerg Care 2007; 11: 307-11.

20. Stewart SL, Secrest JA, Norwood BR, Zachary R. A comparison of endotracheal tube cuff pressures using estimation techniques and direct intracuff measurement. AANA J 2003; 71: 443-7.

21. Sole ML, Aragon D, Bennett M, Johnson RL. Continuous measurement of endotracheal tube cuff pressure: how difficult can it be? AACN Adv Crit Care 2008; 19: 235-43.

22. Blanch PB. Laboratory evaluation of 4 brands of endotracheal tube cuff inflator. Respir Care 2004; 49: 166-73. 